\title{
Anal Torture with Unknown Objects and Electrical Stimuli
}

\section{Siroos Mirzaei ${ }^{1,2 *}$ and Thomas Wenzel ${ }^{2,3}$}

${ }^{1}$ Wilhelminenspital, Department of Nuclear Medicine with PET-Center, Vienna, Austria

${ }^{2}$ Hemayat, Organisation for Support of Survivors of Torture and War, Vienna, Austria

${ }^{3}$ Division of Social Psychiatry, Medical University of Vienna, Austria

\begin{abstract}
Sexual violence in prisons constitutes an act of torture which has been used to a widespread in war situations as in former Yugoslavia and Chechnya. However, especially in Islamic countries sexual violence to men has been neglected because of cultural based stigma of the issue. Sexual torture has serious mental, physical and sexual health consequences.

This paper describes the physical long-term effect of anal torture in an adult man in prison. Examination was performed following the Istanbul Protocol guidelines.
\end{abstract}

A prolonged relaxation time of the anus as a sign of sphincter insufficiency could be an evidence of traumatic damage of anal sphincter by such kind of torture.

Keywords: Sexual torture; Sphincter insufficiency; Anal fissure; Male rape

\section{Introduction}

Male rape, in time of war, is predominantly an assertion of power and aggression rather than an attempt on the part of the perpetrator to satisfy sexual desire [1]. Public awareness of the widespread use of sexual torture as a weapon of war greatly increased after the war in the former Yugoslavia in the early 1990s [2]. In prisons, sexual violence can also be used as an act of torture with the aim to damage the victim's social identity, and make him feel ashamed of himself. The focus of medical literature has been more on the sexual torture of women than of men. Especially in Islamic countries sexual violence to men has been neglected and must be seen as a taboo issue. In a recent study based on in-depth interviews with health professionals and data from the medical records of centers providing care to refugees and victims of torture, the authors found evidence of rape and other forced sexual acts, full or partial castration, genital beatings and electroshock. Only few men admitted having being sexually tortured or were seeking help [2].

\section{Case Report}

A 43 year old male was exposed to sexual torture during his imprisonment in his home country Iran three years prior to our examination. Unknown objects were inserted in his anal canal. An electrical cable was inserted into his after and using a generator. $\mathrm{He}$ was subjected to incremental electrical stimuli which were perceived as painful and disagreeable anal itchiness.

The clinical examination was based on the UN and World Medical Association supported "Istanbul Protocol" guidelines [3] and conducted about 36 months after alleged torture. Special care was taken in this context to avoid undue stress, giving the client prior information and control of the progress of examination steps as requested by the protocol.

In the clinical rectal examination there is an irregular shape of the anus due to anal scars between 6-12 $\mathrm{h}$ and fecal soiling attributed to sphincter insufficiency (Figure 1). The images were taken about 30 seconds after the separation of buttocks by the patient and the anus is still not closed, which is longer than the physiological relaxation time, again consistent with injuries as described by the patient, following established standards [4].

Other possible causes such as constipation had been excluded in the history of the patient. Results were seen as consistent with the alleged form of torture. Manometry of the rectum was not available at the time of the interview.

Due to the severe distress of the client, psychotherapy had been initiated, and the indication for surgical intervention has been discussed with the patient.

\section{Discussion}

In Bosnia- Herzegovina, Croatia and Iraq, male rape and sexual torture has been used as a weapon of war with dire consequences for the victim's mental, physical, and sexual health. Testimonies collected at the Medical Centre for Human Rights in Zagreb and reports received from Iraq make it clear that prisoners in these conflicts have been

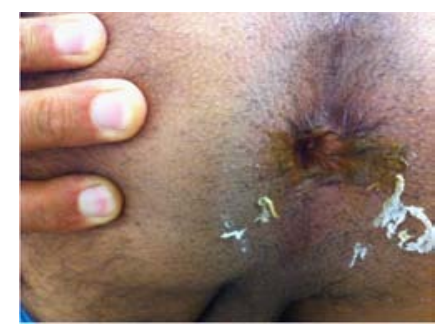

Figure 1: Irregular shape of the anus due to anal scars between $6-12 \mathrm{~h}$ and stool contamination on reason of sphincter insufficiency.

*Corresponding author: Siroos Mirzaei, Wilhelminenspital, Department of Nuclear Medicine with PET-Center Montleartstrasse 37, A-1171 Vienna, Austria, Tel: +43-149150-3608; Fax: +43-1-49150-3609; E-mail: siroos.mirzaei@wienkav.at

Received March 02, 2013; Accepted March 29, 2013; Published April 01, 2013

Citation: Mirzaei S, Wenzel T (2013) Anal Torture with Unknown Objects and Electrical Stimuli. J Trauma Treat 2: 162. doi:10.4172/2167-1222.1000162

Copyright: (C) 2013 Mirzaei S, et al. This is an open-access article distributed under the terms of the Creative Commons Attribution License, which permits unrestricted use, distribution, and reproduction in any medium, provided the original author and source are credited. 
exposed to sexual humiliation, as well as to systematic sexual torture [5].

However, many victims of sexual torture and especially male victims with Islamic background would undergo medical examination to substantiate their claim of being exposed to this form of violence. In this case report the patient suffered from the after-effects of anal torture and agreed to be examined, consenting also that his case report would get published. To our best knowledge, this case report is the first study with a visual documentation on the physical impact of sexual torture in men.

The prolonged relaxation time of anus is a sign of traumatic damage of anal sphincter and could be used also as evidence in the forensic documentation. Creating an open and not stigmatizing environment in the medical setting following the Istanbul protocol guidelines can permit survivors to reconfirm their dignity as a victim of inacceptable treatment, recover from shame and guilt feelings, and find support and treatment.

\section{Conclusion}

In accordance with reports on war crimes in the last few decades sexual torture is a still evident practice, even in Islamic countries, where men are also not excluded from this act of torture, as it could be shown in this case report. A prolonged relaxation time of anus as a sign of sphincter insufficiency could be an evidence of traumatic damage of anal sphincter by torture.

\section{References}

1. Zawati HM (2007) Impunity or immunity: wartime male rape and sexual torture as a crime against humanity. Torture 17: 27-47.

2. Oosterhoff $P$, Zwanikken $P$, Ketting $E$ (2004) Sexual torture of men in Croatia and other conflict situations: an open secret. Reprod Health Matters 12: 68-77.

3. http://www.ohchr.org/Documents/Publications/training8Rev1en.pdf

4. (1998) Glossary of terms and the interpretations of findings for child sexua abuse evidentiary examinations. American Professional Society on the Abuse of Children.

5. http://www.ohchr.org/Documents/Publications/training8Rev1en.pdf 